Review

\title{
Molecular and structural aspects of clinically relevant mutations related to the approved non-nucleoside inhibitors of HIV-1 reverse transcriptase
}

\author{
Stefano Alcaro ${ }^{\mathrm{a}}$, Claudia Alteri ${ }^{\mathrm{b}}$, Anna Artese ${ }^{\mathrm{a}, *}$, Francesca Ceccherini-Silberstein $^{\mathrm{b}}$, \\ Giosuè Costa ${ }^{a}$, Francesco Ortuso ${ }^{a}$, Lucia Parrotta ${ }^{a}$, Carlo Federico Perno ${ }^{b}$, Valentina Svicher $^{b}$ \\ a Laboratorio di Chimica Farmaceutica Computazionale - Dipartimento di Scienze Farmacobiologiche Università "Magna Græcia" di Catanzaro, \\ Campus Universitario, Viale Europa, 88100 Catanzaro, Italy \\ b Dipartimento di Medicina Sperimentale e Biochimica, Università “Tor Vergata”, Via Montpellier, 1, 00133 Roma, Italy
}

\section{A R T I C L E I N F O}

\section{Article history:}

Received 19 November 2010

Received in revised form 7 January 2011

Accepted 7 January 2011

\section{Keywords:}

HIV-1

HAART

Reverse transcriptase

NNRTIs

Resistance

\begin{abstract}
A B S T R A C T
In recent years relevant progress has been made in the treatment of HIV-1 with a consequent decrease in mortality. The availability of potent antiretroviral drugs and the ability of viral load assays that accurately evaluate the true level of viral replication, have led to a better understanding of pathogenesis of the disease and how to obtain improved therapeutic profiles. The highly active antiretroviral therapy (HAART), based on a combination of three or more antiretroviral drugs, has radically changed the clinical outcome of HIV. In particular, reverse transcriptase non-nucleoside inhibitors (NNRTIs) play an essential role in most protocols and are often used in first line treatment. The high specificity of these inhibitors towards HIV1 has increased the number of structural and molecular modeling studies of enzyme complexes and that have led to chemical syntheses of more selective second and third-generation NNRTIs. However, a considerable percentage of new HIV-1 infections are caused by the emergence of drug-resistant mutant viruses that complicate treatment strategies.

In this review we discuss relevant clinical and structural aspects for the management of antiretroviral drug resistance, with detailed explanations of mechanisms and mutation patterns useful to better understand the relation between drug resistance and therapy failure.
\end{abstract}

(c) 2011 Elsevier Ltd. All rights reserved.

\section{Contents}

1. Introduction.

2. The reverse transcriptase (RT)

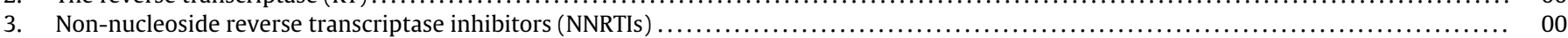

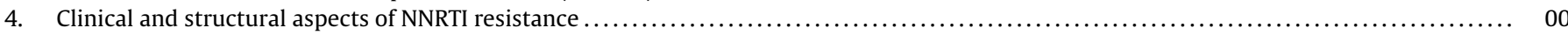

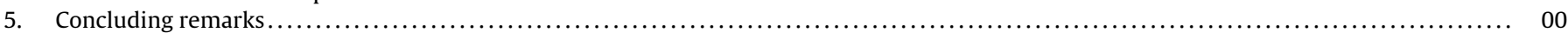

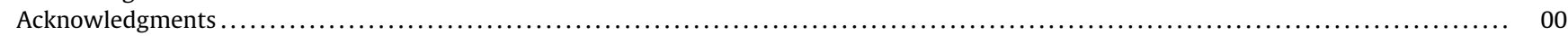

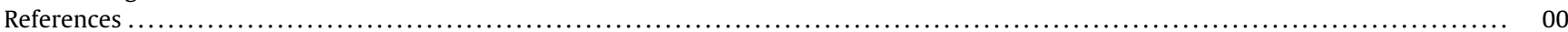

\section{Introduction}

The human immunodeficiency virus type 1 (HIV-1) is the etiological agent of the acquired immunodeficiency syndrome (AIDS). To infect its hosts, this retrovirus uses three key enzymes necessary in its life cycle: reverse transcriptase (RT), integrase (IN) and protease (PR). During its spread among humans, HIV-1 has exhibited an extraordinary degree of genetic variability mainly due to the error prone nature of the reverse transcriptase and to the high viral

\footnotetext{
* Corresponding author. Tel.: +39 0961 3694297; fax: +39 0961391490

E-mail address: artese@unicz.it (A. Artese).
}

production and turnover rates (Sarafianos et al., 2004). Among the different areas of the viral genome, the pol gene, encoding enzymes such as RT and PR, is subjected to not only natural evolutionary forces but also selective pressure imposed by pharmacological treatment (Condra et al., 1995; Eshleman et al., 2002; Wegner et al., 2000; Lecossier et al., 2005). The variation within individuals has led to the generation of diverse HIV-1 subtypes complicating the development of effective drugs and vaccines. Presently, combinations of different inhibitors, called HAART (highly active antiretroviral therapy), are useful to inhibit such a moving target (Sarafianos et al., 2004).

The HIV-1 RT is responsible for the conversion of the single stranded RNA genome into a double stranded DNA that is later 
integrated into the host genomic DNA. The enzyme is composed by two subunits, p66 and p51, which have the same $\mathrm{N}$ terminus (Wang et al., 1994). The p66 subunit contains the active sites for both polymerase and RNase $\mathrm{H}$, while the $\mathrm{p} 51$ primarily plays a structural role. Highly conserved regions of p66 act as a clamp in positioning the template-primer. The primer grip is responsible for the appropriate placement of the primer terminus at the polymerase active site and it is involved in translocation of the template-primer. Appropriate binding/positioning of the template-primer is also important for appropriate cleavage of the RNA-DNA substrate by the RNase $\mathrm{H}$ activity of RT (Kohlstaedt et al., 1992).

Due to its essential role in HIV replication, RT is a major target for antiretroviral drug development (Parniak and SluisCremer, 2000). More than half of the currently approved drugs for the treatment of HIV-1 infection are RT inhibitors. In particular, they consist of a group of seven nucleoside-analogue reverse transcriptase inhibitors (NRTIs: ZDV-zidovudine, d4T-stavudine, 3TC-lamivudine, ddI-didanosine, ABC-abacavir, ddC-zalcitabine, FTC-emtricitabine), one acyclic nucleoside monophosphate (TDFtenofovir), and four approved non-nucleoside analogue reverse transcriptase inhibitors (NNRTIs: NVP-nevirapine, EFV-efavirenz, DLV-delavirdine, ETV-etravirine). There also is a fifth forthcoming analogue (RPV-rilpivirine) (Parniak and Sluis-Cremer, 2000; De Clercq, 2004, 2009; Balzarini, 2004). Rilpivirine, also known as TMC278, is an investigational diarylpyrimidine non-nucleoside reverse transcriptase inhibitor (NNRTI) with a high genetic barrier to the development of resistance in vitro. It is being studied in ongoing Phase IIb and Phase III trials for the treatment of HIV infection in treatment-naive patients. Rilpivirine retained a 50\% effective concentration against all of the following mutations: L100I, K103N, V106A, G190A, G190S, K101E, Y181C, Y188L, L100I+K103N, and K103N + Y181C. Eight mutations have been shown to be required to reduce susceptibility to RPV (Natap.org Conference Reports, 2005).

\section{The reverse transcriptase $(\mathrm{RT})$}

In the Protein Data Bank (PDB) (http://www.rcsb.org) there are several crystal structures of free, unbound HIV-1 RTs (Hsiou et al., 1996; Rodgers et al., 1995). The three-dimensional structure of the p66 subunit is often compared to a right hand, with fingers (amino acids 1-85 and 118-155), a palm (residues 86-117 and 156-237) and thumb (amino acids 238-318) domains (Kohlstaedt et al., 1992). The polymerase active site with its three aspartic acid residues (110, 185 and 186) and the YMDD region (Y183-M184D185-D186) is located into the palm domain. X-ray structures of RT co-crystallized with a conserved oligonucleotide and a dNTP (Huang et al., 1998) or double-stranded DNA (Jacobo-Molina et al., 1993) have highlighted that the nucleic acid passes into the cleft behind the fingers and in front of the thumb domain. The RNase $\mathrm{H}$ subdomain (amino acids 427-560), located next to the catalytic domain, makes contact with the connection domain (amino acids 319-426) also involved in interactions with the nucleic acid and the p51 subunit. Conformational perturbations occurring in an allosteric site, known as NNRTI-binding pocket (NNRTI-BP), can remarkably influence the polymerase activity of the catalytic triad. Crystallographic studies of HIV-1 RT have revealed important features of the enzymatic structure and function, including details of NNRTI binding. Although there are significant chemical differences between the first-generation NNRTIs, (tivirapine, loviride, and nevirapine), all three inhibitors bind to HIV-1 RT in the NNRTI-BP via a common binding mode defined as "butterfly-like" (Kohlstaedt et al., 1992; Ding et al., 1995).

The NNRTI-BP is situated between the $\beta 6-\beta 10-\beta 9$ and $\beta 12-\beta 13-\beta 14$ sheets in the palm subdomain of the p66 subunit approximately $10 \AA$ away from the catalytic site. This cleft has a predominately hydrophobic nature with substantial aromatic character (Y181, Y188, F227, W229 and Y232) but also contains several hydrophilic residues (K101, K103, S105, D192 and E224 of the p66 subunit and $\mathrm{E} 138$ of the $\beta 7-\beta 8$ loop of the p51 subunit). A possible solvent accessible entrance to the NNRTI-BP is located at the p66/p51 heterodimer interface surrounded by residues L100, K101, K103,V179 and Y181 of the $\mathrm{p} 66$ subunit and E138 of the $\mathrm{p} 51$ subunit (Ren et al., 1995; Hsiou et al., 1996). The NNRTI-BP is not present in structures of HIV-1 RT with no bound inhibitors; this "closed form" of the NNRTI-BP corresponds to a hydrophobic core and it can be expanded to permit NNRTI binding to RT. The NNRTI bound "open form" of the pocket might correspond to other states of RT required for viral replication. Expansion or opening of the NNRTI-BP region involves large displacements of Y181, Y188 and W229 aromatic side chains and a rotation of the $\beta 12-\beta 13-\beta 14$ sheet, with a consequent shift of the "primer grip" (Das et al., 1996; Tantillo et al., 1994). Moreover the NNRTI-BP is elastic and its conformation depends on the size and specific chemical structure and binding mode of the drug; the overall structure of RT is conformationally flexible according to the nature of the bound inhibitor.

\section{Non-nucleoside reverse transcriptase inhibitors (NNRTIs)}

The first NNRTI compounds described in 1989 were HEPT [1-(2-2-hydroxyethoxymethyl)-6-(phenylthio)thymine], but originally they were designed as NRTIs (Miyasaka et al., 1989). Only later it was found that they would share a common mechanism of action with TIBO (tetrahydroimidazo[4,5,1$\mathrm{jkj}][1,4]$ benzodiazepin-2(1H)-one and -thione) compounds, identified as potent and selective HIV-1 RT inhibitors (Kukla et al., 1991; Pauwels et al., 1990). Over time several studies have been carried out to better understand the mechanisms by which NNRTIs inhibit the HIV-1 RT and HIV-1 replication; resolution of co-crystals of HIV-1 RT with different NNRTIs, enzyme inhibition kinetics, RT dimerization, and others have been performed (Sluis-Cremer and Tachedjian, 2008). The binding of these inhibitors is known to induce a structural distortion in RT thus blocking its polymerase activity. In particular, the conformation of the RT catalytic site is impacted by NNRTI binding. The position of the YMDD motif is influenced especially by the D185 and D186 residues that coordinate the $\mathrm{Mg}^{2+}$ ions in the active site (Esnouf et al., 1995), as well as that of the structural elements that form the "primer grip" (Hsiou et al., 1996).

Another major modification observed upon NNRTI binding is the decrease of thumb mobility in p66 subunit. This change could result in slowing or even preventing the translocation of the primer/template and the elongation of the nascent DNA strand (Kohlstaedt et al., 1992; Tachedjian and Goff, 2003; Tantillo et al., 1994).

NNRTIs appear to interfere with different steps in the reverse transcriptase reaction. In particular some NNRTIs, such as efavirenz and the diarylpyrimidine derivatives dapivirine and etravirine, resulted as able to inhibit the late stages of HIV-1 replication by interfering with Gag-Pol polyprotein processing (Figueiredo et al., 2006). Other compounds such as 1-(3-cyclopenten-1-yl)methyl-6-(3,5-dimethylbenzoyl)5-ethyl-2,4 pyrimidinedione have been shown to inhibit both RT-mediated reverse transcription and viral entry (Buckheit et al., 2007). Recently Grobler et al. (2007) demonstrated that in vitro NNRTIs strongly inhibited plus-strand initiation. Furthermore, these inhibitors were found to completely abrogate dNTP binding to RT related to RNA PPT primer/DNA template substrate showing a modest decrease in the dNTP affinity for RT associated with the DNA PPT primer/DNA template. 
Although NNRTIs are potent and exhibit desirable low toxicity, their efficacy is limited by the emergence of resistant viral strains (Clavel and Hance, 2004; Shafer, 2002). Resistance is the cause and/or the consequence of treatment failure. It is related to three crucial factors: (a) HIV infection is characterized by a very high replication rate; (b) HIV-1 RT lacks exonucleolytic proof-reading functionality; (c) viral population in an infected person is highly heterogeneous (Perelson et al., 1996; Roberts et al., 1988; Clavel and Hance, 2004). As a consequence, the production of a mutant at each nucleotide position in the viral genome occurs daily. Thus, monotherapy regimens readily select the mutants in the replicating population that are resistant to the administered drug(s). In addition, since an extensive cross-resistance can be rapidly observed within each class of antiretroviral drugs, the selected drug resistant quasispecies compromise the effectiveness of subsequent HAART regimens (Antinori et al., 2002; Hertogs et al., 2000; Shulman and Winters, 2003).

Adherence to treatment is another key-factor that can influence the development of NNRTI resistance. In particular, a recent prospective clinical trial showed that the relationship between adherence and resistance is class-specific. For the class of NNRTI, initial virological failure with resistance is more likely at lower level of adherence (Gardner et al., 2010; Paredes et al., 2010). Thus, this finding supports that low adherence to NNRTI-containing regimens represents a strong contributor to NNRTI resistance development.

Initially, mutations associated with resistance to NNRTIs, both in vitro and in vivo, were all located in the NNRTI binding pocket specifically in the p66 subunit areas (amino acid sequences 98-108, 178-190 and 225-238) (Soriano and de Mendoza, 2002). The most prevalent substitutions observed in viruses after NNRTI therapeutic failure are K103N and Y181C (Cheung et al., 2004; Tambuyzer et al., 2009). On the other hand mutations such as Y318F, placed outside the originally identified domains (Harrigan et al., 2002), and $\mathrm{E} 138 \mathrm{G} / \mathrm{K} / \mathrm{Q}$ even when it is present in the $\mathrm{p} 51$ subunit only (Jonckheere et al., 1994), cause resistance to NNRTIs. Over 40 amino acid substitutions have been associated with NNRTI resistance, in vitro and in vivo (Ceccherini-Silberstein et al., 2007; Tambuyzer et al., 2009; Johnson et al., 2009; Stanford HIV Drug Resistance Database). Recently, other mutations, such as N348I, G333E/D, $\mathrm{A} 360 \mathrm{~T}$ and $\mathrm{A} 371 \mathrm{~V}$, located in the connection domain of the p66 subunit (between the thumb and the RNase $\mathrm{H}$ domains) have been observed in NRTI + NNRTI-treated patients (Nikolenko et al., 2007; Santos et al., 2008; Waters et al., 2009). In particular, it was observed that HIV-1 susceptibility to nevirapine not efavirenz nor etravirine, was decreased by the presence of mutations in the connection domain (N348I) (Brehm et al., 2009; Gupta et al., 2009; Nikolenko et al., 2010; Vingerhoets et al., 2009).

As a consequence, NNRTI resistance mutations are directly involved in the binding of the molecules into the pocket, by altering size, shape, and polarity of different parts of the NNRTI-BP or, indirectly, by affecting the access to this binding site. However, some of these substitutions have also been found to influence functionalities of RT other than DNA polymerization. For example, V106A causes a reduction in the rate of RNA 5'-end and DNA 3'-end directed RNaseH cleavage activities (Archer et al., 2000; Gerondelis et al., 1999), while the Y181C mutation shows rate acceleration of RNaseH cleavage activities (Archer et al., 2000).

Nevirapine and delavirdine are the first generation NNRTIs approved by the FDA in 1996 and 1997, respectively, while efavirenz, approved in 1998, belongs to the second generation of NNRTI. Presently, the most commonly used drugs for first line HAART treatments are nevirapine and efavirenz. Conversely, delavirdine has never been registered in Europe and therefore not prescribed. They are characterized by a low genetic barrier to resistance development. In current protocols it is necessary their combination with at least two other fully active non-NNRTI antiretroviral drugs, and resistance to one of them precludes successive use of the other first generation NNRTIs (Jochmans et al., 2009). With the aim to obtain a better resistance profile and an increased genetic barrier, further research was prompted to discover next generation NNRTIs due to their crucial role in HAART protocols. Etravirine was the third generation NNRTI to be approved by the FDA. In contrast to the previous generation NNRTIs, whose efficiency can be compromised by a single mutation causing resistance, etravirine is characterized by a higher genetic barrier to resistance. Thus for this reason, it is also used in treating-experienced patients carrying NNRTI-resistant HIV-1 strains (Tibotec Inc., 2008). There are currently four next generation NNRTIs in clinical development: rilpivirine, IDX- 899, RDEA-428, and lersivirine. Fig. 1 below shows the chemical structures and the binding pockets of the NNRTIs.

Nevirapine (NVP) is a dipyridodiazepinone inhibitor of HIV-1. It was discovered in 1990 (Merluzzi et al., 1990) and it is effective in treating naïve patients when used as part of a fully suppressive regimen (Lange, 2003). The most commonly selected resistance mutations in vivo are related to RT positions 103, 106, 108, 181, 188 and 190 (Richman et al., 1994; Wainberg, 2003). Y181 and Y188 play an important role in stabilizing NVP binding through stacking interactions between their aromatic side-chains and the pyridine groups of the inhibitor. Not surprisingly, mutations at residues 181 (i.e. Y181C or Y181I) or 188 (i.e. Y188C, Y188I, Y188L or Y188H) confer high-level resistance to the drug (Ren et al., 1995).

Efavirenz (EFV) is a benzoxazinone discovered in 1995 (Young et al., 1995). It is the most used NNRTI in treating naïve patients in combination with two NRTIs. The most frequently selected mutation in EFV failures is $\mathrm{K} 103 \mathrm{~N}$, however other substitutions commonly observed also resulted, such as V108I, P225H or L100I, K101E, K101Q, Y188H, Y188L, G190S, G190A and G190E (Bacheler et al., 2000). Recently it was co-formulated with tenofovir disoproxil fumarate and emtricitabine in one tablet marketed as Atripla $^{\mathrm{TM}}$ (Goicoechea and Best, 2007; Huang et al., 2003). The contribution of stacking interactions in EFV binding to the viral RT is minimized. Upon binding, it makes direct or water-mediated hydrogen bonds with the protein backbone of K101 and K103 (Ren et al., 2000).

Etravirine (ETV) belongs to the family of diarylpyrimidine (DAPY) compounds (it was discovered after a long lead optimization step by researchers at the Janssen Research Foundation and Tibotec in 2001) (Ludovici et al., 2001). ETV resistance profile was further evaluated by testing the molecule against thousands of NNRTI resistant HIV-1 clinical strains (Rimsky et al., 2009). In vitro, ETV shows a higher genetic barrier to the development of resistance when compared to NVP and EFV (Vingerhoets et al., 2005). ETVRT crystallographic complexes with the K103N mutation allowed for a better understanding of the molecule binding mode to the enzyme. Such a diarylpyrimidine analogue can bind in at least two conformationally distinct modes. Moreover, its torsional flexibility ("wiggling") permits access to numerous conformational variants it can undergo to reposition/reorient itself (translation and rotation) within the pocket ("jiggling") (Das et al., 2004). These conformational adaptations proved critical for potency against wild-types and for a wide range of drug-resistant mutant HIV-1 RTs. ETV was found to be effective against virus containing combinations of frequent drug resistance mutations (K101E/K103N or K103N/Y181C) (Andries et al., 2004). Several substitutions such as L100I, V179I/F, Y181C, G190E, M230L and Y318F, were observed in ETV-resistant isolates. Clinical studies have shown that high-level resistance to ETV is related to the accumulation of at least two drug resistant mutations. Additionally, a decreased virological response to ETV was observed in the presence of three or more RT DNA polymerase domain baseline substitutions (including V90I, A98G, L100I, K101E, K101P, V106I, V179D, V179F, Y181C, Y181I, Y181V, G190A 
A<smiles>Cc1ccnc2c1NC(=O)c1cccnc1N2C1CC1</smiles>

B

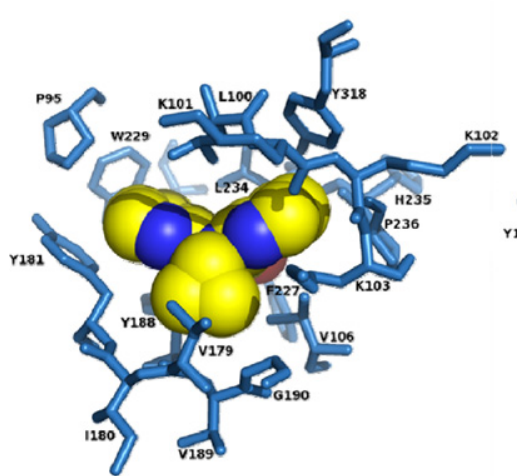

$B$<smiles>C[C@]1(C#CC2CC2)OC(=O)Nc2ccc(Cl)cc21</smiles><smiles>Cc1cc(C#N)cc(C)c1Oc1nc(Nc2ccc(C#N)cc2)nc(N)c1Br</smiles>
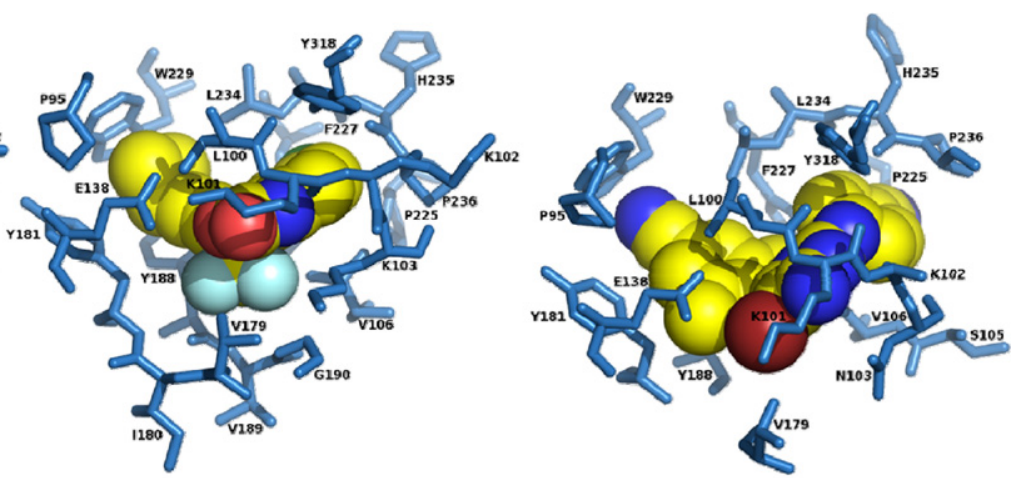

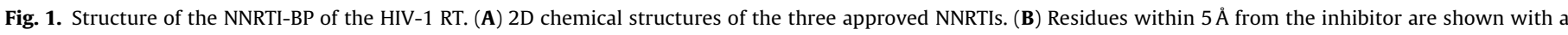

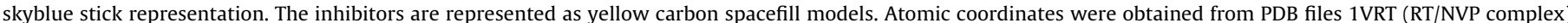

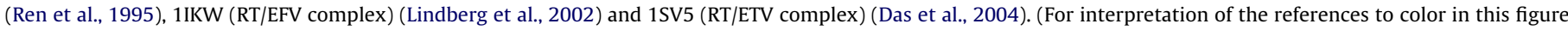
legend, the reader is referred to the web version of the article.)

and G190S) (Vingerhoets et al., 2007). Single mutations resulted associated with a reduced number of ETV alternate binding configurations since the drug can accommodate into the NNRTI-BP (likely due to its high flexibility/conformation freedom). These observations support the finding that ETV resistance requires multiple mutations. The most common substitutions associated to NNRTIs resistance are represented in Fig. 2.

Since the complex network of factors contributing to NNRTI resistance have not yet been completely elucidated, it is conceivable that more mutations (and association of mutations)

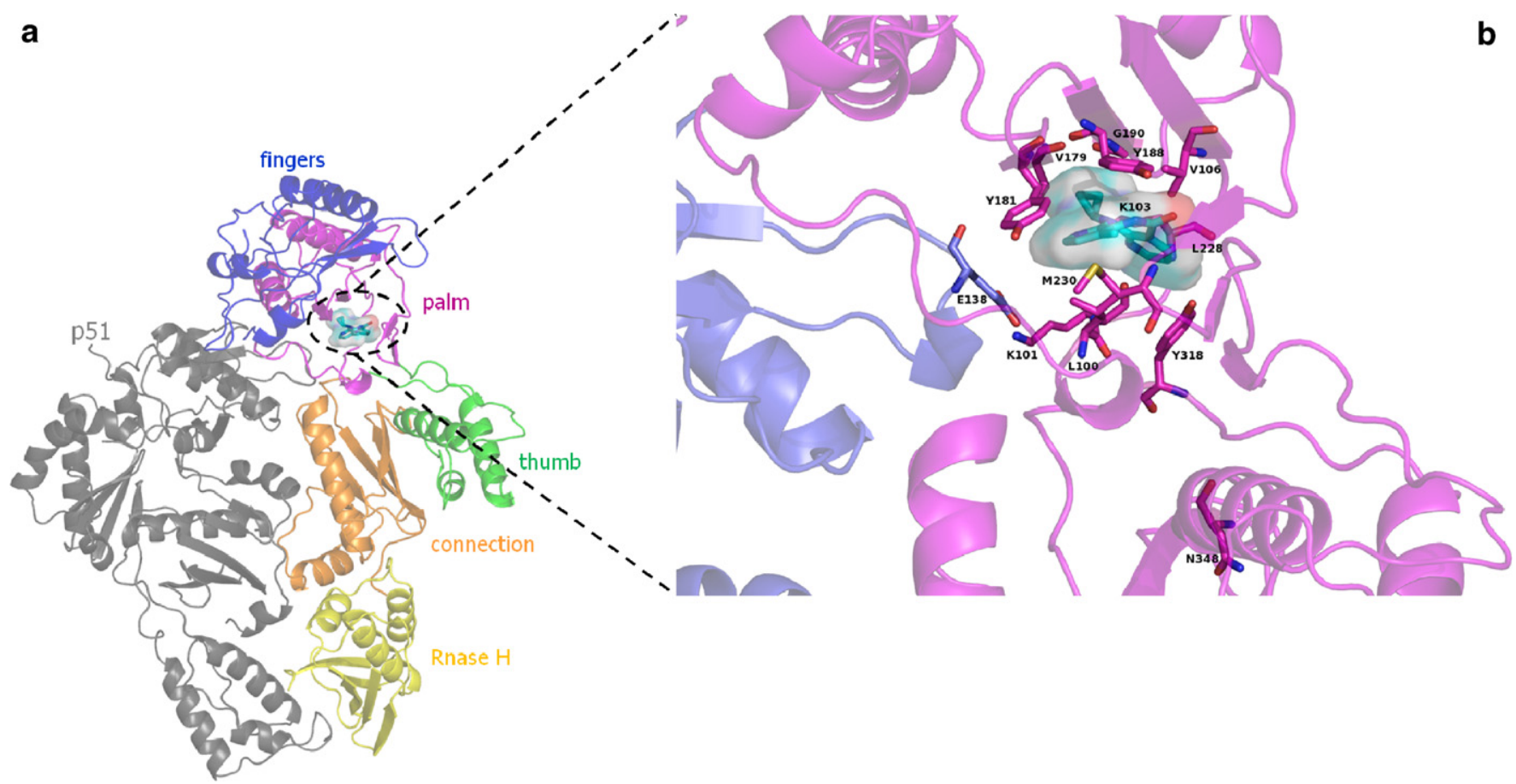

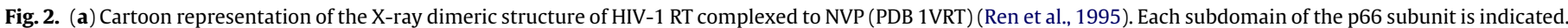

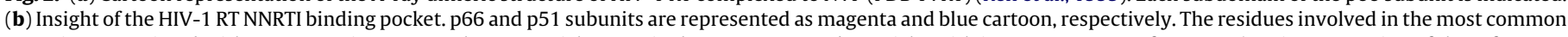

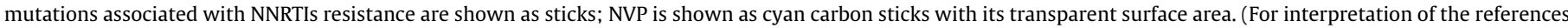
to color in this figure legend, the reader is referred to the web version of the article.) 
Table 1

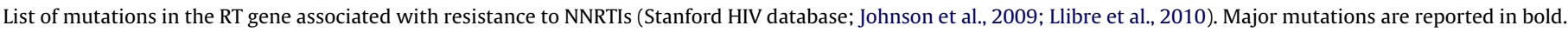

\begin{tabular}{|c|c|c|c|c|c|c|c|c|c|c|c|c|c|c|c|c|c|c|c|}
\hline 90 & 98 & 100 & 101 & 103 & 106 & 108 & 138 & 179 & 181 & 188 & 189 & 190 & 221 & 225 & 227 & 230 & 234 & 238 & 318 \\
\hline \multicolumn{20}{|l|}{$E F V$} \\
\hline \multirow[t]{3}{*}{ G } & & I & E & $\mathbf{N}$ & A & I & & D & C & $\mathbf{L}$ & & A & & H & C & $\mathbf{L}$ & & $\mathrm{T}$ & \\
\hline & & & $\mathbf{P}$ & $S$ & I & & & $\mathrm{E}$ & I & $\mathrm{H}$ & & $S$ & & & & & & & \\
\hline & & & & & M & & & $\mathrm{F}$ & V & C & & $\mathbf{E}$ & & & & & & & \\
\hline \multicolumn{20}{|l|}{ ETV } \\
\hline \multirow[t]{7}{*}{ I } & G & I & E & $\mathrm{N}$ & A & I & A & D & C & C & I & A & $\mathrm{Y}$ & $\mathrm{H}$ & C & $\mathbf{L}$ & I & $\mathrm{N}$ & $\mathrm{F}$ \\
\hline & & & $\mathrm{H}$ & $S$ & I & & G & E & I & $\mathrm{H}$ & & C & & & $\mathrm{L}$ & & & $\mathrm{T}$ & \\
\hline & & & $\mathrm{N}$ & $\mathrm{T}$ & $\mathrm{M}$ & & K & $\mathbf{F}$ & $\mathrm{F}$ & $\mathbf{L}$ & & $\mathbf{E}$ & & & & & & & \\
\hline & & & $\mathbf{P}$ & & & & $Q$ & $\mathrm{~L}$ & $S$ & & & $Q$ & & & & & & & \\
\hline & & & $Q$ & & & & M & $\mathbf{V}$ & & & & $\mathrm{S}$ & & & & & & & \\
\hline & & & & & & & $\mathrm{T}$ & & & & & $\mathrm{T}$ & & & & & & & \\
\hline & & & & & & & & & & & & $\mathrm{V}$ & & & & & & & \\
\hline \multicolumn{20}{|l|}{$N V P$} \\
\hline & G & I & $\mathbf{E}$ & $\mathbf{N}$ & A & I & & D & C & C & & A & & & C & $\mathbf{L}$ & & $\mathbf{T}$ & \\
\hline & & & $\mathbf{P}$ & & $\mathbf{M}$ & & & E & I & $\mathbf{L}$ & & $\mathbf{S}$ & & & $\mathrm{L}$ & & & & \\
\hline & & & & & & & & $\mathrm{F}$ & $\mathbf{V}$ & $\mathbf{H}$ & & $\mathbf{E}$ & & & & & & & \\
\hline
\end{tabular}

than currently known, are involved in therapeutic failure. Several studies have contributed to our current knowledge of the RT drug-related variants and of the enzyme conserved regions mainly involved in proper dimerization and polymerase function (Ceccherini-Silberstein et al., 2005). In a recent publication (Alcaro et al., 2010), our innovative computational approach GBPM (Ortuso et al., 2006) was applied to RT in order to design new pharmacophoric models helpful in the drug discovery of more effective anti-RT inhibitors with more favorable resistance profiles. Consequently, the elucidation of the molecular recognition of certain currently approved NNRTIs, in the presence of known mutations responsible for resistance, is critical for the development of superior inhibitors.

The present review will discuss advances in our knowledge of the pathways involved in drug resistance-associated mutations, updates on RT and inhibitors used in HAART protocols, and molecular observations useful for the design of new leads. A particular focus will be on [RT.NNRTI] crystallographic models in order to better rationalize the structural aspects related to therapeutic failure.

\section{Clinical and structural aspects of NNRTI resistance}

NNRTIs are an important class of antiretroviral agents used for the treatment of HIV-1 infection. These agents (in particular EFV) have become a preferred therapy option for the treatment of drug-naïve patients and have gained increased popularity over protease inhibitor-based antiretroviral therapy. Nevertheless, the first and second generation NNRTI (NVP and EFV) are particularly susceptible to the development of resistance. In particular, different clinical trials showed that the incidence of NNRTI mutations, in patients failing initial antiretroviral regimens with EFV, is roughly 50\% (Gallant et al., 2004; Gulick et al., 2007; Riddler et al., 2008).

A different scenario is observed for the last generation NNRTI ETV characterized by a higher genetic barrier than older NNRTIs (Llibre et al., 2008). Analyses from the DUET studies have identified 17 mutations (E138A, V90I, A98G, L100I, K101E, K101P, K101H, M230L, V106I, V179D, V179F, V179T, Y181C, Y181I, Y181V, G190A, G190S) correlated with a decreased virological response to ETV. The presence of 3 or more mutations are required to drastically affect virological response to this drug (Vingerhoets et al., 2008; Cohen et al., 2009). Conversely, ETV has been shown to retain full activity against K103N which is one of the most common NNRTI resistance mutations detected (Table 1) (Andries et al., 2004). Of note, Y181I is a natural polymorphism in HIV-2, that could confer an intrinsic resistance to ETV.

A unique characteristic of NNRTI resistance mutants is their limited impact on HIV-1 replication capacity. Indeed, different studies have shown that the majority of NNRTI resistance mutations, including K103N, L100I, V197D, and Y181C/I, do not severely impair viral fitness (Gerondelis et al., 1999; Huang et al., 2002; Collins et al., 2004; Gatanaga et al., 2006; Archer et al., 2000; Antinori et al., 2001).

The limited impact on viral replication allows NNRTI resistance mutations to persist in predominant circulating viral strains both in drug-naïve patients and in patients that interrupted antiretroviral regimen. Indeed, NNRTI resistance mutations are the most common resistance mutations detected in drug-naïve patients, and have been shown to hamper the achievement of virologial success of a first line NNRTI containing regimen (Kuritzkes et al., 2008). Similarly, it has been shown that NNRTI resistant mutations K103N, $\mathrm{Y} 181 \mathrm{C} / \mathrm{I}$, and G190A persist (up to 7 years as reported for K103N) in two-thirds of patients who interrupted therapy with NNRTIs (Joly et al., 2004; Capetti et al., 2005; Gianotti et al., 2005).

Another clinically relevant topic is represented by the impact of minority variants resistant to NNRTI on virological response to the first line of antiretroviral regimens. The detection of preexisting minority Y181C variants significantly increased the risk of failure of an initial EFV-based regimen in patients with optimal compliance with ART. Conversely, other studies showed no association between the presence of minority NNRTI variants and virological failure on early therapy (Metzner et al., 2007; Metzner et al., 2009; Peuchant et al., 2008). The discrepant results obtained by these studies could be explained by the different quantity of detected minority resistant variants. At this regard, Goodman and his group have recently defined the threshold quantity of K103N minority resistant variants above that in which patients fail the NNRTI containing therapy (Goodman et al., 2009). By multiplying the proportion of virus with $\mathrm{K} 103 \mathrm{~N}$ in RT and the viral load, a threshold of $>2000$ copies $/ \mathrm{ml}$ of drug-resistance mutations has been correlated with an increased risk of viral failure to an EFV-containing regimen. Thus, this finding highlights the importance to establish a cut-off below which the risk of failure declines.

We analyzed [NVP.RT], [EFV.RT] and [ETV.RT] complexes, selecting the crystallographic PDB structures with the code 1VRT (Ren et al., 1995) (resolution 2.20 Å), 1IKW (Lindberg et al., 2002) (resolution $3.00 \AA$ ) and 1SV5 (Das et al., 2004), respectively.

Represented in Fig. 1, is the binding pocket of the X-ray structure of the three approved NNRTIs with the RT residues mainly involved in drug interactions. A detailed list of the interacting amino acids is reported in Table 2 . Structural studies comparing a series of NNRTIs having widely variant inhibitory potencies have shown significant conformational differences in the inhibitor pocket (Hopkins et al., 1996). In particular Y181 and Y188 are known to largely contribute to drug stabilization through hydrophobic contacts. 
Table 2

List of the analyzed inhibitor interacting residues in [NVP.RT], [EFV.RT] and [ETV.RT] crystallographic complexes 1VRT (Ren et al., 1995), 1IKW (Lindberg et al., 2002) and 1SV5 (Das et al., 2004). ${ }^{\mathrm{a}, \mathrm{b}, \mathrm{c}}$

\begin{tabular}{llll}
\hline Res $^{c}$ & NVP & EFV & ETV \\
\hline L100 & $a$ & $a$ & $a$ \\
K101 & $a$ & $a^{*}$ & $a^{*}$ \\
K102 & - & - & $a^{*}$ \\
K103 & - & $a$ & - \\
V106 & $a$ & $a$ & $a$ \\
E138 & - & - & $b$ \\
V179 & $a$ & $a$ & $a$ \\
Y181 & $a$ & $a$ & $a$ \\
Y188 & $a$ & $a$ & $a$ \\
G190 & $a$ & - & - \\
P225 & - & - & $a$ \\
F227 & $a$ & $a$ \\
W229 & - & $a$ & - \\
L234 & $a$ & $a$ & $a$ \\
H235 & $a$ & $a$ & - \\
P236 & - & $a$ & - \\
Y318 & $a$ & $a$ & $a$ \\
\hline
\end{tabular}

a $\mathrm{a}$ and $\mathrm{b}$ indicate, respectively, p66 and $\mathrm{p} 51 \mathrm{RT}$ subunits pertinent to the specified residues establishing nonbonded contacts.

$\mathrm{b}$ The asterisks point out hydrogen bonds.

c The residue is reported as in the WT sequence.

Specifically, these tyrosine residues, involved in aromatic ring $\pi$ stacking interactions with first generation NNRTIs, are crucial since single mutation is related to a drastic reduction in inhibitor binding affinity (Ren et al., 2001). In contrast, amino acids K101 and K103, located at the NNRTI-BP entry, play a crucial role in hydrophilic interactions. Thus, substitutions at K103N and K101E cause strong resistance to multiple NNRTIs including the first generation NNRTI NVP(D'Aquila et al., 2002; Ren et al., 2007). Several crystallographic studies have shown that NVP binds close to the $\beta$-hairpin between strands 9 and 10 in the palm subdomain of p66 that contains the highly conserved YMDD motif. The drug binding pocket is constituted by the central 6, 9 and 10 strands and residues F227 to P236 located in strands $12-14$ and Y319 placed at the C-terminus of $\beta$-strand 15. Amino acids L100-K103, V179 and S191 of the p66 subunit and E138 of the p51 subunit form a solvent-accessible entrance to the cavity (Ren et al., 1995). NVP can establish more than 30 protein interactions. In particular, enzyme-inhibitor interaction is primarily stabilized through hydrophobic interactions among $\pi$-electron donor groups of the ligand and aromatic side chain residues of the binding pocket (Y181, Y188) or within the side chains of L100, V106 and V179 (Campiani et al., 2002). Moreover, NVP accommodation of the WT complex results in a well stabilized interaction with G190 located in the binding pocket $\beta$-sheet and found to be essential for interactions with the drug (Paolucci et al., 2007). In addition, drug-specific electrostatic attractions contribute to the final strength of binding.

Also in the WT [EFV.RT] complex, many of the inhibitor's interactions with the enzyme involve a series of hydrophobic interactions. Specifically the cyclopropyl-propynyl group is surrounded by the aromatic side chains of Y181, Y188, F227 and W229. The benzoxazin-2-one ring is located between the side chains of L100 and V106 and can participate edge-on with Y318 and V179 while with its nitrogen, can establish a van der Waals interaction with the side chain of K103 (Ren et al., 2000). Comparing the crystallographic structures of WT and K103N RTs complexed to EFV (Lindberg et al., 2002), the mutation K103N was found to have minimal influence on the bound conformation of an inhibitor. However, several studies have shown that in the absence of a NNRTI, a hydrogen bond between Y188 and N103 closes the entrance to the NNRTI binding pocket, efficiently reducing its access to multiple NNRTIs (Hsiou et al., 2001; Ren et al., 2000; Lindberg et al., 2002) and stabilizing the enzyme unbound state (Hsiou et al., 2001; Rodriguez-Barrios and Gago, 2004).

Interestingly a recent computational method was performed to study the interactions between EFV and residues in the binding pocket for WT HIV-1 RT (Nunrium et al., 2005). The results showed a net attractive interaction between EFV and surrounding residues while lysine at position 101 demonstrated a stronger interaction than others. This contact plays an important role in the stability of the inhibitor and strengthens the inhibitory affinity of EFV over other NNRTIs. It was found that the small loss of binding to the K103N mutant by EFV can be addressed to a slightly weakened attractive interaction between the drug and K101 residue (Srivab and Hannongbua, 2008).

The difficulty of generating co-crystal structures of RT with ETV has been reported several times (Das et al., 2004; Das et al., 2008; Bauman et al., 2008). However, in a recent publication new X-ray crystallographic structures of WT and K103N have been solved and deposited in the PDB with codes 3MEC and 3MED, respectively (Lansdon et al., 2010). ETV was shown to be involved in key interactions with L100, V106, V179, P225, L234, P236 and Y318 residues of the NNRTI-BP. Moreover, the p-cyano group of the diarylpyrimidine is located in a hydrophobic area between F227 and W229 side chains, while its secondary amine can establish a hydrogen bond with K101.

In both analyzed K103N models (PDB 1SV5 and 3MED) ETV was found to also interact with E138 of the p51 subunit; such a contact was missing with first generation NNRTIs. E138 is the only residue of the p51 subunit that interacts with NNRTIs even if it does not directly interact with all inhibitors. Such a residue is part of the $\beta 7-\beta 8$ loop in HIV- 1 RT and is a highly conserved amino acid sequence which the pyrimidine core found near E138. Mutagenesis analyses highlighted the pivotal structural and functional roles of E138 in NNRTI-BP stabilization as much as its mutation significantly reduced viral infectivity (Pandey et al., 2002). In particular E138R was recently identified as a novel substitution and it was found related to a negative effect on ETV binding due to the longer basic side chain (Azijn et al., 2010).

All 3D figures were performed using PyMOL graphics and modeling package ver 0.99 (DeLano, 2002). The contact analysis of the drugs with the interacting RT residues in the studied crystallographic complexes was carried out by the Maestro GUI interface of MacroModel ver 7.2 (Schrödinger Inc., 1998-2001; Mohamadi et al., 1990).

\section{Concluding remarks}

In conclusion, the first generation NNRTIs nevirapine and efavirenz remain a cornerstone of first line HAART. With etravirine approval, a shift in treatment paradigms has been observed since for the first time a non-nucleoside inhibitor shows durable effectiveness in patients with NNRTI resistant HIV-1 infection. NNRTI resistant mutations have been shown to be directly involved in the binding of the drugs in the pocket, by altering size, shape and polarity of different parts of the NNRTI-BP or, indirectly, by preventing the access to the pocket. However, some of the most significant substitutions have also been found to influence functionalities of RT other than DNA polymerization. This review describes in detail the effects of clinically relevant mutations associated to the failure of the approved NNRTIs, particularly emphasizing on the most frequent K103N. Promising results show that next generation NNRTIs, such as rilpivirine, which is studied in treating naïve patients, have an increased genetic barrier to the development of resistance and have a convenient dosing schedule with potential for co-formulation with other antiretroviral drugs. 


\section{Acknowledgments}

This study was supported by grants from CHAIN, Collaborative HIV and Anti-HIV Drug Resistance Network, Integrated Project no.223131, funded by the European Commission Framework 7 Program.

We thank Dr. Alfredo Mellace, Department of Chemistry, Nassau Community College NY (USA) for the grammar and style revision of the manuscript.

\section{References}

Alcaro, S., Artese, A., Ceccherini-Silberstein, F., Chiarella, V., Dimonte, S., Ortuso, F. Perno, C.F., 2010. Computational analysis of human immunodeficiency virus (HIV) type-1 reverse transcriptase crystallographic models based on significant conserved residues found in highly active antiretroviral therapy (HAART)treated patients. Curr. Med. Chem. 17, 290-308.

Andries, K., Azijn, H., Thielemans, T., Ludovici, D., Kukla, M., Heeres, J., et al., 2004. TMC125, a novel next-generation non-nucleoside reverse transcriptase inhibitor active against non-nucleoside reverse transcriptase inhibitor-resistant human immunodeficiency virus type 1. Antimicrob. Agents Chemother. 48, 4680-4686.

Antinori, A., Liuzzi, G., Cingolani, A., Bertoli, A., Di Giambenedetto, S., Trotta, M.P., Rizzo, M.G., Girardi, E., De Luca, A., Perno, C.F., 2001. Drug-resistant mutants of HIV-1 in patients exhibiting increasing CD4 cell count despite virological failure of highly active antiretroviral therapy. AIDS 15, 2325-2327.

Antinori, A., Zaccarelli, M., Cingolani, A., Forbici, F., Rizzo, M.G., Trotta, M.P., Di Giambenedetto, S., Narciso, P., Ammassari, A., Girardi, E., De Luca, A., Perno, C.F., 2002. Cross-resistance among nonnucleoside reverse transcriptase inhibitors limits recycling efavirenz after nevirapine failure. AIDS Res. Hum. Retrovir. 18, 835-838.

Archer, R.H., Dykes, C., Gerondelis, P., Lloyd, A., Fay, P., Reichman, R.C., Bambara, R.A., Demeter, L.M., 2000. Mutants of human immunodeficiency virus type 1 (HIV-1) reverse transcriptase resistant to non-nucleoside reverse transcriptase inhibitors demonstrate altered rates of RNase $\mathrm{H}$ cleavage that correlate with HIV-1 replication fitness in cell culture. J. Virol. 74, 8390-8401.

Azijn, H., Tirry, I., Vingerhoets, J., de Bethune, M.P., Kraus, G., Boven, K., Jochmans, D., et al., 2010. TMC278, a next-generation nonnucleoside reverse transcriptase inhibitor (NNRTI), active against wild-type and NNRTI-resistant HIV-1. Antimicrob. Agents Chemother. 54, 718-727.

Bacheler, L.T., Anton, E.D., Kudish, P., Baker, D., Bunville, J., Krakowski, K., et al., 2000. Human immunodeficiency virus type 1 mutations selected in patients failing efavirenz combination therapy. Antimicrob. Agents Chemother. 44, 2475-2484.

Balzarini, J., 2004. Current status of the non-nucleoside reverse transcriptase inhibitors of human immunodeficiency virus type 1 . Curr. Top. Med. Chem. 4 , 921-944.

Bauman, J.D., Das, K., Ho, W.C., Baweja, M., Himmel, D.M., Clark Jr., A.D., Oren, D.A., Boyer, P.L., et al., 2008. Crystal engineering of HIV-1 reverse transcriptase for structure-based drug design. Nucleic Acids Res. 36, 5083-5092.

Brehm, J., Sheen, C.W., Hughes, M., Lalama, C., Haubrich, R., Riddler, S., Sluis-Cremer, N., Mellors, J., 2009. Virologic failure of regimens containing two NRTIs plus efavirenz is not associated with the selection of mutations in the connection or RNase H domains of reverse transcriptase. Antivir. Ther. 14 (Suppl. 1), A34 (Abstract 32).

Buckheit Jr., R.W., Hartman, T.L., Watson, K.M., Kwon, H.S., Lee, S.H., Lee, J.W., Kang, D.W., Chung, S.G., Cho, E.H., 2007. The structure-activity relationships of 2,4(1H,3H)-pyrimidinedione derivatives as potent HIV type 1 and type 2 inhibitors. Antivir. Chem. Chemother. 18, 259-275.

Campiani, G., Ramunno, A., Maga, G., Nacci, V., Fattorusso, C., Catalanotti, B., Morelli, E., Novellino, E., 2002. Non-nucleoside HIV-1 reverse transcriptase (RT) inhibitors: past, present, and future perspectives. Curr. Pharm. Des. 8, 615-657.

Capetti, A.F., Gabris, A.I., Drago, L., Vigevani, G.M., 2005. Can a K103N HIV strain stably overcome the wild type in the absence of non-nucleoside reverse transcriptase inhibitor selective pressure? AIDS 19, 633-634.

Ceccherini-Silberstein, F., Gago, F., Santoro, M., Gori, C., Svicher, V., RodriguezBarrios, F., et al., 2005. High sequence conservation of human immunodeficiency virus type-1 reverse transcriptase under drug pressure despite the continuous appearance of mutations. J. Virol. 79, 10718-10729.

Ceccherini-Silberstein, F., Svicher, V., Sing, T., Artese, A., Santoro, M.M., et al., 2007. Characterization and structural analysis of novel mutations in human immunodeficiency virus type 1 reverse transcriptase involved in the regulation of resistance to nonnucleoside inhibitors. J. Virol. 81, 11507-11519.

Cheung, P.K., Wynhoven, B., Harrigan, P.R., 2004. Which HIV-1 drug resistance mutations are common in clinical practice? AIDS Rev. 6, 107-116.

Clavel, F., Hance, A.J., 2004. HIV drug resistance. N. Engl. J. Med. 350, 1023-1035.

Cohen, C.J., Berger, D.S., Blick, G., et al., 2009. Efficacy and safety of etravirine (TMC125) in treatment-experienced HIV-1 infected patients: 48-week results of a phase IIb trial. AIDS 23, 423-426.

Collins, J.A., Thompson, M.G., Paintsil, E., Ricketts, M., Gedzior, J., Alexander, L., 2004. Competitive fitness of nevirapine-resistant human immunodeficiency virus type 1 mutants. J. Virol. 78, 603-611.
Condra, J.H., Schleif, W.A., Blahy, O.M., Gabryelski, L.J., et al., 1995. In vivo emergence of HIV-1 variants resistant to multiple protease inhibitors. Nature 374 , 569-571.

D’Aquila, R.T., Schapiro, J.M., Brun-Vezinet, F., Clotet, B., Conway, B., Demeter, L.M., et al., 2002. Drug resistance mutations in HIV-1. Top. HIV Med. 10, 21-25.

Das, K., Ding, J., Hsiou, Y., Clark Jr., A.D., Moereels, H., et al., 1996. Crystal structures of 8-Cl and 9-Cl TIBO complexed with wild-type HIV-1 RT and 8-Cl TIBO complexed with the Tyr181Cys HIV-1 RT drug-resistant mutant. J. Mol. Biol. 264 1085-1100.

Das, K., Clark Jr., A.D., Lewi, P.J., Heeres, J., De Jonge, M.R., Koymans, L.M., et al., 2004. Roles of conformational and positional adaptability in structure-based design of TMC125-R165335 (etravirine) and related non-nucleoside reverse transcriptase inhibitors that are highly potent and effective against wild-type and drug-resistant HIV-1 variants. J. Med. Chem. 47, 2550-2560.

Das, K., Bauman, J.D., Clark Jr., A.D., Frenkel, Y.V., Lewi, P.J., Shatkin, A.J., Hughes, S.H., Arnold, E., 2008. High-resolution structures of HIV-1 reverse transcriptase/TMC278 complexes: strategic flexibility explains potency against resistance mutations. Proc. Natl. Acad. Sci. U.S.A. 105, 1466-1471.

De Clercq, E., 2004. Antiviral drugs in current clinical use. J. Clin. Virol. 30, 115-133.

De Clercq, E., 2009. Another ten stories in antiviral drug discovery (part C): "Old" and "new" antivirals, strategies, and perspectives. Med. Res. Rev. 29, 611-645.

DeLano, W.L., 2002. The PyMOL Molecular Graphics System. DeLano Scientific, San Carlos, CA, USA, http://www.pymol.org.

Ding, J., Das, K., Moereels, H., Koymans, L., Andries, K., et al., 1995. Structure of HIV-1 RT/TIBO R 86183 complex reveals similarity in the binding of diverse nonnucleoside inhibitors. Nat. Struct. Biol. 2, 407-415.

Eshleman, S.H., Gonzales, M.J., Becker-Pergola, G., Cunningham, S.C., Guay, L.A., Jackson, J.B., Shafer, R.W., 2002. Identification of Ugandan HIV type 1 variants with unique patterns of recombination in pol involving subtypes A and D. AIDS Res. Hum. Retroviruses 18, 507-511.

Esnouf, R.M., Ren, J., Ross, C., Jones, Y., Stammers, D., Stuart, D., 1995. Mechanism of inhibition of HIV-1 reverse transcriptase by non-nucleoside inhibitors. Nat. Struct. Biol. 2, 303-308.

Figueiredo, A., Moore, K.L., Mak, J., Sluis-Cremer, N., De Bethune, M.P., Tachedjian, G., 2006. Potent non-nucleoside reverse transcriptase inhibitors target HIV-1 Gag-Pol. PLoS Pathog. 2, e119.

Gallant, J.E., Staszewski, S., Pozniak, A.L., DeJesus, E., Suleiman, J.M., Miller, M.D., Coakley, D.F., Lu, B., et al., 2004. Efficacy and safety of tenofovir DF vs stavudine in combination therapy in antiretroviral-naive patients: a 3-year randomized trial. JAMA 292, 191-201.

Gardner, E.M., Hullsiek, K.H., Telzak, E.E., Sharma, S., Peng, G., Burman, W.J., MacArthur, R.D., et al., 2010. Terry Beirn Community Programs for Clinical Research on AIDS and the International Network for Strategic Initiatives in Global HIV Trials. Antiretroviral medication adherence and class-specific resistance in a large prospective clinical trial. AIDS 24, 395-403.

Gatanaga, H., Hachiya, A., Kimura, S., Oka, S., 2006. Mutations other than $103 \mathrm{~N}$ in human immunodeficiency virus type 1 reverse transcriptase (RT) emerge from K103R polymorphism under non-nucleoside RT inhibitor pressure. Virology 344 , 354-362.

Gerondelis, P., Archer, R.H., Palaniappan, C., Reichman, R.C., Fay, P.J., Bambara, R.A., Demeter, L.M., 1999. The P236L delavirdine-resistant human immunodeficiency virus type 1 mutant is replication defective and demonstrates alterations in both RNA 5'-end- and DNA 3'-end-directed RNase $\mathrm{H}$ activities. J. Virol. 73, 5803-5813.

Gianotti, N., Galli, L., Boeri, E., Maillard, M., Serra, G., Ratti, D., Gallotta, G., Vacchini, D., Tremolada, Y., et al., 2005. In vivo dynamics of the K103N mutation following the withdrawal of non-nucleoside reverse transcriptase inhibitors in human immunodeficiency virus-infected patients. New Microbiol. 28, 319-326.

Goicoechea, M., Best, B., 2007. Efavirenz/emtricitabine/tenofovir disoproxil fumarate fixed-dose combination: first-line therapy for all? Exp. Opin. Pharmacother. 8, 371-382

Goodman, D.D., Margo, N.A., Mc Coll, D.J., Miller, M.D., Borroto-Esodo, K., Svarovkaia, E.S., 2009. Pre-exsisting low levels of K103N HIV-1 RT mutation above a threshold is associated with virological failure in treatment naïve patients undergoing EFV-containing antiretroviral treatment. Antivir. Ther. 14 (Suppl. 1), A43.

Grobler, J.A., Dornadula, G., Rice, M.R., Simcoe, A.L., Hazuda, D.J., Miller, M.D., 2007 HIV-1 reverse transcriptase plus-strand initiation exhibits preferential sensitivity to non-nucleoside reverse transcriptase inhibitors in vitro. J. Biol. Chem. 282, 8005-8010.

Gulick, R.M., Ribaudo, H.J., Shikuma, C.M., Lalama, C., Schackman, B.R., Meyer 3rd W.A., Acosta, E.P., et al., 2007. ACTG 5095: three vs four-drug antiretroviral regimens for the initial treatment of HIV-1 infection - a randomized clinical trial. JAMA 296, 769-781.

Gupta, S., Fransen, S., Frantzell, A., Coakley, E., Stawiski, E., Petropoulos, C.J., Huang, W., 2009. C-terminal reverse transcriptase mutations N348I and T369I reduce etravirine susceptibility, but only in the presence of additional NNRTI mutations. Antivir. Ther. 14 (Suppl. 1), A140 (Abstract 119).

Harrigan, P.R., Salim, M., Stammers, D.K., Wynhoven, B., Brumme, Z.L., McKenna, P., Larder, B., Kemp, S.D., 2002. A mutation in the $3^{\prime}$ region of the human immunodeficiency virus type 1 reverse transcriptase (Y318F) associated with nonnucleoside reverse transcriptase inhibitor resistance. J. Virol. 76, 6836-6840.

Hertogs, K., Bloor, S., Kemp, S.D., Van den Eynde, C., Alcorn, T.M., Pauwels, R., Van Houtte, M., Van Staszewski, S., Miller, V., Larder, B.A., 2000. Phenotypic and genotypic analysis of clinical HIV-1 isolates reveals extensive protease inhibitor cross-resistance: a survey of over 6000 samples. AIDS 14, 1203 1210 . 
Hopkins, A.L., Ren, J., Esnouf, R.M., Willcox, B.E., Jones, E.Y., et al., 1996. Complexes of HIV-1 reverse transcriptase with inhibitors of the HEPT series reveal conformational changes relevant to the design of potent non-nucleoside inhibitors. J. Med. Chem. 39, 1589-1600.

Hsiou, Y., Ding, J., Das, K., Clark, A.D., Hughes Jr., S.H., Arnold, E., 1996. Structure of unliganded HIV-1 reverse transcriptase at $2.7 \AA$ A resolution: implications of conformational changes for polymerization and inhibition mechanisms. Structure 4, 853-860.

Hsiou, Y., Ding, J., Das, K., Clark Jr., A.D., Boyer, P.L., Lewi, P., Janssen, P.A., et al., 2001. The Lys103Asn mutation of HIV-1 RT: a novel mechanism of drug resistance. J. Mol. Biol. 309, 437-445.

Huang, H., Chopra, R., Verdine, G.L., Harrison, S.C., 1998. Structure of a covalently trapped catalytic complex of HIV-1 reverse transcriptase: implications for drug resistance. Science 282, 1669-1675.

Huang, W., Wrin, T., Gamarnik, A., Beauchaine, J., Whitcomb, J.M., Petropoulos, C.J., 2002. Reverse transcriptase mutations that confer non-nucloside reverse transcriptase inhibitor resistance may also impair replication capacity. Antivir. Ther. 7, S60.

Huang, W., Gamarnik, A., Limoli, K., Petropoulos, C.J., Whitcomb, J.M., 2003. Amino acid substitutions at position 190 of human immunodeficiency virus type 1 reverse transcriptase increase susceptibility to delavirdine and impair virus replication. J. Virol. 77, 1512-1523.

Jacobo-Molina, A., Ding, J., Nanni, R.G., Clark Jr., A.D., Lu, X., Tantillo, C., Williams, R.L., Kamer, G., Ferris, A.L., Clark, P., et al., 1993. Crystal structure of human immunodeficiency virus type 1 reverse transcriptase complexed with doublestranded DNA at $3.0 \AA$ Å resolution shows bent DNA. Proc. Natl. Acad. Sci. U.S.A. 90, 6320-6324.

Jochmans, D., Vingerhoets, J., Arnoult, E., Geeraert, L., Guillemont, J., 2009. Human immunodeficiency virus type 1 non-nucleoside reverse transcriptase inhibitors. In: LaFemina, R.L. (Ed.), Antiviral Research: Strategies in Antiviral Drug Discovery. ASM Press, Washington, pp. 33-50.

Johnson, V.A., Brun-Vezinet, F., Clotet, B., Gunthard, H.F., Kuritzkes, D.R., Pillay, D., Schapiro, J.M., Richman, D.D., 2009. Update of the drug resistance mutations in HIV-1: December 2009. Top. HIV Med. 17, 138-145.

Joly, V., Descamps, D., Peytavin, G., Touati, F., Mentre, F., Duval, X., Delarue, S., Yeni, P., Brun-Vezinet, F., 2004. Evolution of human immunodeficiency virus type 1 (HIV-1) resistance mutations in non-nucleoside reverse transcriptase inhibitors (NNRTIs) in HIV-1-infected patients switched to antiretroviral therapy without NNRTIs. Antimicrob. Agents Chemother. 48, 172-175.

Jonckheere, H., Taymans, J.M., Balzarini, J., Velázquez, S., Camarasa, M.J., Desmyter, J., De Clercq, E., Anné, J., 1994. Resistance of HIV-1 reverse transcriptase against $\left[2^{\prime}, 5^{\prime}\right.$-bis-O-(tert-butyldimethylsilyl)-3'-spiro- $5^{\prime \prime}-\left(4^{\prime \prime}\right.$-amino$1^{\prime \prime}, 2^{\prime \prime}$-oxathiole- $2^{\prime \prime}, 2^{\prime \prime}$-dioxide) (TSAO) derivatives is determined by the mutation Glu138 $\rightarrow$ Lys on the p51 subunit. J. Biol. Chem. 269, 25255-25258.

Kohlstaedt, L.A., Wang, J., Friedman, J.M., Rice, P.A., Steitz, T.A., 1992. Crystal structure at $3.5 \AA$ resolution of HIV-1 reverse transcriptase complexed with an inhibitor. Science 256, 1783-1790.

Kukla, M.J., Breslin, H.J., Diamond, C.J., Grous, P.G., Chih, Y.H., et al., 1991. Synthesis and anti-HIV-1 activity of 4,5,6,7-tetrahydro-5-methylimidazo[4,5,1jk][1,4]benzodiazepin-2(1H)-on e (TIBO) derivatives. 2. J. Med. Chem. 34, 3187-3197.

Kuritzkes, D.R., Lalama, C.M., Ribaudo, H.J., Marcial, M., Meyer 3rd, W.A., Shikuma, C., Johnson, V.A., Fiscus, S.A., et al., 2008. Preexisting resistance to non-nucleoside reverse-transcriptase inhibitors predicts virologic failure of an efavirenzbased regimen in treatment-naïve HIV-1-infected subjects. J. Infect. Dis. 197, 867-870.

Lange, J.M., 2003. Efficacy and durability of nevirapine in antiretroviral drug naive patients. J. Acquir. Immune Defic. Syndr. 34 (Suppl. 1), S40-S52.

Lansdon, E.B., Brendza, K.M., Hung, M., Wang, R., Mukund, S., Jin, D., et al., 2010. Crystal structures of HIV-1 reverse transcriptase with Etravirine (TMC125) and Rilpivirine (TMC278): implications for drug design. J. Med. Chem. 53, 4295-4299.

Lecossier, D., Shulman, N.S., Morand-Joubert, L., Shafer, R.W., Joly, V., Zolopa, A.R., Clavel, F., Hance, A.J., 2005. Detection of minority populations of HIV-1 expressing the $\mathrm{K} 103 \mathrm{~N}$ resistance mutation in patients failing nevirapine. J. Acquir. Immune Defic. Syndr. 38, 37-42.

Lindberg, J., Sigurdsson, S., Lowgren, S., Andersson, H.O., Sahlberg, C., Noreen, R., Fridborg, K., Zhang, H., Unge, T., 2002. Structural basis for the inhibitory efficacy of efavirenz (DMP-266), MSC194 and PNU142721 towards the HIV-1 RT K103N mutant. Eur. J. Biochem. 269, 1670-1677.

(a) Ludovici, D.W., Kukla, M.J., Grous, P.G., Krishnan, S., Andries, K., de Béthune, M.P., et al., 2001. Evolution of anti-HIV drug candidates. Part 1. From alphaanilinophenylacetamide (alpha-APA) to imidoyl thiourea (ITU). Bioorg. Med. Chem. Lett. 11, 2225-2228;

(b) Ludovici, D.W., Kavash, R.W., Kukla, M.J., Ho, C.Y., Ye, H., De Corte, B.L., Andries, K., de Béthune, M.P., et al., 2001. Evolution of anti-HIV drug candidates. Part 2. Diaryltriazine (DATA) analogues. Bioorg Med. Chem. Lett. 11, 2229-2234;

(c) Ludovici, D.W., De Corte, B.L., Kukla, M.J., Ye, H., Ho, C.Y., Lichtenstein, M.A., et al., 2001. Evolution of anti-HIV drug candidates. Part 3. Diarylpyrimidine (DAPY) analogues. Bioorg. Med. Chem. Lett. 11, 2235-2239.

Schrödinger Inc., 1998-2001. Maestro v. 4.1. Schrödinger Inc., Portland, OR, USA.

Mohamadi, F., Richards, N.G.J., Guida, W.C., Liskamp, R., Lipton, M., Caufield, C., et al., 1990. MacroModel: an integrated software system for modeling organic and bioorganic molecules using molecular mechanics. J. Comput. Chem. 11, 440467.
Llibre, J.M., Santos, J.R., Puig, T., Moltó, J., Ruiz, L., Paredes, R., Clotet, B., 2008. Prevalence of etravirine-associated mutations in clinical samples with resistance to nevirapine and efavirenz. J. Antimicrob. Chemother. 62, 909-913.

Llibre, J.M., Schapiro, J.M., Clotet, B., 2010. Clinical implications of genotypic resistance to the Newer antiretroviral drugs in HIV-1-infected patients with virological failure. Clin. Infect. Dis. 50, 872-881.

Merluzzi, V.J., Hargrave, K.D., Labadia, M., Grozinger, K., Skoog, M., et al., 1990. Inhibition of HIV-1 replication by a non-nucleoside reverse transcriptase inhibitor. Science 250, 1411-1413.

Metzner, K.J., Rauch, P., von Wyl, V., Kuster, H., Stellbrink, H.J., Boni, J., Trkola, H., Weber, R., Gunthard, H.F., 2007. Prevalence of minority quasispecies of drugresistant HIV-1 in patients with primary HIV-1 infection in Zurich in the years 2002-2006. Antivir. Ther. 12, S47.

Metzner, J.K., Giulieri, S.G., Knoepfe, S.A., Rauch, P., Burgisser, P., Yerly, S., Gunthard, H.F., Cavassini, M., 2009. Minority quasispecies of drug-resistant HIV-1 that lead to early therapy failure in treatment-Naïve and -adherent patients. Clin. Infect. Dis. 48, 239-247.

Miyasaka, T., Tanaka, H., Baba, M., Hayakawa, H., Walker, R.T., Balzarini, J. De Clercq, E., 1989. A novel lead for specific anti-HIV-1 agents: 1-[(2hydroxyethoxy)methyl]-6-(phenylthio) thymine. J. Med. Chem. 32, 2507-2509.

Natap.org Conference Reports: European HIV Drug Resistance Workshop 2005 Available at: http://www.natap.org/2005/Euro/euro_1.htm.

Nikolenko, G.N., Delviks-Frankenberry, K.A., Palmer, S., Maldarelli, F., Fivash Jr., M.J., Coffin, J.M., Pathak, V.K., 2007. Mutations in the connection domain of HIV 1 reverse transcriptase increase 3'-azido-3'-deoxythymidine resistance. Proc. Natl. Acad. Sci. U.S.A. 104, 317-322.

Nikolenko, G.N., Delviks-Frnakenberry, K.A., Pathak, V.K., 2010. A novel molecular mechanism of dual resistance to nucleoside and non-nucleoside reverse transcriptase inhibitors. J. Virol. 84, 5238-5249.

Nunrium, P., Kuno, M., Saen-oon, S., Hannongbua, S., 2005. Particular interaction between efavirenz and the HIV-1 reverse transcriptase binding site as explained by the ONIOM2 method. Chem. Phys. Lett. 405, 198-202.

Ortuso, F., Langer, T., Alcaro, S., 2006. GBPM: GRID-based pharmacophore model: concept and application studies to protein-protein recognition. Bioinformatics 22, 1449-1455.

Pandey, P.K., Kaushik, N., Singh, K., Sharma, B., Upadhyay, A.K., Kumar, S., Harris, D. Pandey, V.N., 2002. Insertion of a small peptide of six amino acids into the $\beta 7-\beta 8$ loop of the p51 subunit of HIV-1 reverse transcriptase perturbs the heterodimer and affects its activities. Biochemistry 3, 1-18.

Paolucci, S., Baldanti, F., Campanini, G., Cancio, R., Belfiore, A., Maga, G., Gerna, G., 2007. NNRTI selected mutations at codon 190 of human immunodeficiency virus type 1 reverse transcriptase decrease susceptibility to stavudine and zidovudine. Antivir. Res. 76, 99-103.

Paredes, R., Lalama, C.M., Ribaudo, H.J., Schackman, B.R., Shikuma, C., Giguel, F., Meyer 3rd, W.A., Johnson, V.A., et al., 2010. Pre-existing minority drug-resistant HIV-1 variants, adherence, and risk of antiretroviral treatment failure. J. Infect. Dis. 201, 662-671.

Parniak, M.A., Sluis-Cremer, N., 2000. Inhibitors of HIV-1 reverse transcriptase. Adv. Pharmacol. 49, 67-109.

Pauwels, R., Andries, K., Desmyter, J., Schols, D., Kukla, M.J., Breslin, H.J., Raeymaeckers, A., et al., 1990. Potent and selective inhibition of HIV-1 replication in vitro by a novel series of TIBO derivatives. Nature 343, 470-474.

Perelson, A.S., Neumann, A.U., Markowitz, M., Leonard, J.M., Ho, D.D., 1996. HIV-1 dynamics in vivo: virion clearance rate, infected cells life-span, and viral generation time. Science $271,1582-1586$.

Peuchant, O., Thiébaut, R., Capdepont, S., Lavignolle-Aurillac, V., Neau, D., Morlat, P., Dabis, F., Fleury, H., Masquelier, B., 2008. ANRS CO3 aquitaine cohort: transmission of HIV-1 minority-resistant variants and response to first-line antiretroviral therapy. AIDS 22, 1417-1423.

Ren, J., Esnouf, R., Garman, E., Somers, D., Ross, C., Kirby, I., Keeling, J., Darby, G., Jones, Y., Stuart, D., et al., 1995. High resolution structures of HIV-1 RT from four RT-inhibitor complexes. Nat. Struct. Biol. 2, 293-302.

Ren, J., Milton, J., Weaver, K.L., Short, S.A., Stuart, D.I., Stammers, D.K., 2000. Structural basis for the resilience of efavirenz (DMP-266) to drug resistance mutations in HIV-1 reverse transcriptase. Structure 8, 1089-1094.

Ren, J., Nichols, C., Bird, L., Chamberlain, P., Weaver, K., Short, S., Stuart, D.I., Stammers, D.K. 2001. Structural mechanisms of drug resistance for mutations at codons 181 and 188 in HIV-1 reverse transcriptase and the improved resilience of second generation non-nucleoside inhibitors. J. Mol. Biol. 312, 795-805.

Ren, J., Nichols, C.E., Chamberlain, P.P., Weaver, K.L., Short, S.A., Chan, J.H., Kleim, J.P., Stammers, D.K., 2007. Relationship of potency and resilience to drug resistant mutations for GW420867X revealed by crystal structures of inhibitor complexes for wild-type, Leu100Ile, Lys101Glu, and Tyr188Cys mutant HIV-1 reverse transcriptases. J. Med. Chem. 50, 2301-2309.

Richman, D.D., Havlir, D., Corbeil, J., Looney, D., Ignacio, C., Spector, S.A., Sullivan, S. et al., 1994. Nevirapine resistance mutations of human immunodeficiency virus type 1 selected during therapy. J. Virol. 68, 1660-1666.

Riddler, S.A., Haubrich, R., Di Rienzo, A.G., Peeples, L., Powderly, W.G., Klingman, K.L., et al., 2008. Class-sparing regimens for initial treatment of HIV-1 infection. N Engl. J. Med. 358, 2095-2106.

Rimsky, L.T., Azijn, H., Tirry, I., Vingerhoets, J., Mersch, R., Kraus, G., de Béthune, M.P. Picchio, G., 2009. In vitro resistance profile of TMC278, a next generation NNRTI evidence of a higher genetic barrier and a more robust resistance profile than first generation NNRTIs. Antivir. Ther. 14 (Suppl. 1), A141 (Abstract 120).

Roberts, J.D., Bebenek, K., Kunkel, T.A., 1988. The accuracy of reverse transcriptase from HIV-1. Science 242, 1171-1173. 
Rodgers, D.W., Gamblin, S.J., Harris, B.A., Ray, S., Culp, J.S., Hellmig, B., Woolf, D.J., Debouck, C., Harrison, S.C., 1995. The structure of unliganded reverse transcriptase from the human immunodeficiency virus type 1. Proc. Natl. Acad. Sci. U.S.A. $92,1222-1226$.

Rodriguez-Barrios, F., Gago, F., 2004. Understanding the basis of resistance in the irksome Lys103Asn HIV-1 reverse transcriptase mutant through targeted molecular dynamics simulations. J. Am. Chem. Soc. 126, 15386-15387.

Santos, A.F., Lengruber, R.B., Soares, E.A., Jere, A., Sprinz, E., et al., 2008. Conservation patterns of HIV-1 RT connection and RNase H domains: identification of new mutations in NRTI treated patients. PLoS One 3, e1781.

Sarafianos, S.G., Das, K., Hughes, S.H., Arnold, E., 2004. Taking aim at a moving target: designing drugs to inhibit drug-resistant HIV-1 reverse transcriptases. Curr. Opin. Struct. Biol. 14, 716-730.

Shafer, R.W., 2002. Genotypic testing for human immunodeficiency virus type $1 \mathrm{drug}$ resistance. Clin. Microbiol. Rev. 15, 247-277.

Shulman, N., Winters, M., 2003. A review of HIV-1 resistance to the nucleoside and nucleotide inhibitors. Curr. Drug Targets Infect. Disord. 3, 273-281.

Sluis-Cremer, N., Tachedjian, G., 2008. Mechanisms of inhibition of HIV replication by non-nucleoside reverse transcriptase inhibitors. Virus Res. 134, 147-156.

Soriano, V., de Mendoza, C., 2002. Genetic mechanisms of resistance to NRTI and NNRTI. HIV Clin. Trials 3, 237-248.

Srivab, P., Hannongbua, S., 2008. A study of the binding energies of Efavirenz to wild-type and K103N/Y181C HIV-1 Reverse transcriptase based on the ONIOM method. Chem. Med. Chem. 3, 803-811.

Stanford HIV Drug Resistance Database. http://www.hivdbstanford.edu.

Tachedjian, G., Goff, S.P., 2003. The effect of NNRTIs on HIV reverse transcriptase dimerization. Curr. Opin. Investig. Drugs 4, 966-973.

Tambuyzer, L., Azijn, H., Rimsky, L.T., Vingerhoets, J., Lecocq, P., Kraus, G., Picchio, G., de Béthune, M.P., 2009. Compilation and prevalence of mutations associated with resistance to non-nucleoside reverse transcriptase inhibitors. Antivir. Ther. 14, 103-109.

Tantillo, C., Ding, J., Jacobo-Molina, A., Nanni, R.G., Boyer, P.L., et al., 1994. Locations of anti-AIDS drug binding sites and resistance mutations in the three-dimensional structure of HIV-1 reverse transcriptase. Implications for mechanisms of drug inhibition and resistance. J. Mol. Biol. 243, 369-387.

Tibotec Inc., 2008. Intelence (etravirine) Tablets. Full Prescribing Information. Tibotec, Inc., Raritan, NJ, Available at: www.intelence-info.com/intelence/full prescribing-info.html.
Vingerhoets, J., Azijn, H., Fransen, E., De Baere, I., Smeulders, L., Jochmans, D., Andries, K., Pauwels, R., de Béthune, M.P., 2005. TMC125 displays a high genetic barrier to the development of resistance: evidence from in vitro selection experiments. J. Virol. 79, 12773-12782.

Vingerhoets, J., Buelens, A., Peeters, M., Picchio, G., Tambuyzer, L., Van Marck, H. De Smedt, G., Woodfall, B., de Béthune, M.P., 2007. Impact of baseline NNRTI mutations on the virological response to TMC125 in the phase III clinical trials DUET-1 and DUET-2. Antivir. Ther. 12, S34.

Vingerhoets, J., Peeters, M., Azijn, H., Tambuyzer, L., 2008. An update on the list of NNRTI mutations associated with decreased virologic response to etravirine: multivariate analysis on the pooled DUET-1 and DUET-2 clinical trial data. In: XVII International HIV Drug Resistance Workshop, Stiges , Spain, June 10-14 (Abstract 24).

Vingerhoets, J., Tambuyzer, L., Paredes, R., Nijs, S., Clotet, B., Shapiro, J.M., Picchio, G., 2009. Effect of mutations in the RT connection domain on phenotypic susceptibility and virologic response to etravirine. Antivir. Ther. 14 (Suppl. 1), A36 (Abstract 33).

Wainberg, M.A., 2003. HIV resistance to nevirapine and other non-nucleoside reverse transcriptase inhibitors. J. Acquir. Immune Defic. Syndr. 34 (Suppl. 1), S2-S7.

Wang, J., Smerdon, S.J., Jager, J., Kohlstaedt, L.A., Rice, P.A., Friedman, J.M., 1994 Structural basis of asymmetry in the human immunodeficiency virus type 1 reverse transcriptase heterodimer. Proc. Natl. Acad. Sci. U.S.A. 91, 72427246.

Waters, J.M., O'Neal, W., White, K.L., Wakeford, C., Lansdon, E.B., Harris, J. Svarovskaia, E.S., Miller, M.D., Borroto-Esoda, K., 2009. Mutations in the thumb-connection and RNase $H$ domain of HIV type- 1 reverse transcriptase of antiretroviral treatment-experienced patients. Antivir. Ther. 14, 231-239.

Wegner, S.A., Brodine, S.K., Mascola, J.R., Tasker, S.A., et al., 2000. Prevalence of genotypic and phenotypic resistance to anti-retroviral drugs in a cohort of therapy-naïve HIV-1 infected US military personnel. AIDS 14, 1009-1015.

Young, S.D., Britcher, S.F., Tran, L.O., Payne, L.S., Lumma, W.C., Lyle, T.A., Huff, J.R., et al., 1995. L-743,726 (DMP-266): a novel, highly potent non-nucleoside inhibitor of the human immunodeficiency virus type 1 reverse transcriptase. Antimicrob. Agents Chemother. 39, 2602-2605. 